Article

\title{
Establishment of a Laminated Crushed Products Function and Numerical Analysis
}

\author{
Guochen Duan, Boqiang Shi *, Yanhua Shen and Guoqing Yu \\ School of Mechanical Engineering, University of Science and Technology Beijing, Beijing 100083, China; \\ b20160239@xs.ustb.edu.cn (G.D.); yanhua_shen@ces.ustb.edu.cn (Y.S.); b20140324@xs.ustb.edu.cn (G.Y.) \\ * Correspondence: shiboqiang@ustb.edu.cn; Tel.: +86-010-6233-2865
}

Received: 8 January 2019; Accepted: 15 February 2019; Published: 1 March 2019

\begin{abstract}
A model of the relative compression ratio for single-particle crushed products, based on the distinct element method (DEM) and numerical analysis, was established to describe precisely the crushed products of granular particles during laminated crushing. The relative compression ratio model was used to describe the functional relationship between the total compression ratio and the single-particle compression ratio, which can be described by lognormal distribution. The single-particle crushed products model was used to describe the functional relationship between the single-particle compression ratio and the distribution of single-particle crushed products. The distribution of single-particle crushed products was described by a three-parameter beta distribution. On the basis of the above model, the function of laminated crushed products of granular particles was established. According to the simulation results of EDEM under confining pressure, a functional relationship between total compression ratio, particle size, and height of the granular particles for laminated crushed products of granular particles was built. It was proved that the function of the theoretical particle size distribution coefficient of laminated crushed products of granular particles was not too different from the actual value determined by simulation. The function is universal and can be used to provide a theoretical basis and a design reference for the design of cone crushers, high-pressure roller mills, and other crushing equipment.
\end{abstract}

Keywords: distinct element method (DEM); crushed products; three-parameter beta distribution; numerical analysis

\section{Introduction}

Granular mechanics studies the balance and motion of granular particles and is widely used in industrial technology [1]. Granular mechanics is used to investigate mineral processing, crushing, and other aspects. In recent years, as the social demand of various mineral materials and building materials has been increasing, the throughput of crushing equipment is growing. The development trends of ore crushing have been changing to obtain high efficiency and address energy-saving concerns. The recently introduced crushing theory is focused on "more crushing and less grinding", and "replacing grinding with crushing". Therefore, it is essential to research the internal mechanisms and characteristics of granular materials to design and manufacture adequate crushing equipment.

The cone crusher is one of the most widely used crushing machines. The material is crushed into small particles by eccentric extrusion achieved by moving the cone in a crushing chamber. Because of the poor working conditions, the major components of the cone crusher are easily damaged as a consequence of impact and heavy load. In the traditional design of cone crushers, the design of working parameters is conservative. Although the safety factor is important, a conservative design may reduce the crushing efficiency and cause low productivity, increased weight, increased energy consumption and other consequences. Therefore, it is necessary to optimize the design. Output is an 
important optimization objective. The particle size and shape of the crushed products are the main indexes for evaluating the performance of a cone crusher. The granularity and shape of the crushing products directly affect the economic benefits for the manufacturers and reflect the performance of a cone crusher. To quantitatively describe the particle size distribution of crushed products, Broadbent and Callcott [2,3] proposed the fragmentation function and the selection function in 1956. Lynch [4] put forward the matrix model of crushing equipment on this basis in 1977, which perfected the cycle of mineral crushing and grinding. Bengtsson et al. [5] described the granularity of crushed products by granularity selection function, granularity crushing function, and matrix model.

At present, there are optimization studies on output [6-8]. Crushing is widely used in industrial production. Modeling and analysis of crushing product distribution under different conditions have been studied [9-11]. When a granular material is broken, the movement of the products is complex, and the distribution varies. Computer-aided computing and distinct element method (DEM) were introduced to analyze the movement and the distribution of crushed products, and there is already a great number of related researches. Es-Haghi et al. [12] predicted the particle size distribution of the crushed products of a jaw crusher by using PFC3D, which is a three-dimensional particle flow code software that models the movement and interactions of particles by DEM. The particle size distribution model was verified by test results. Quist et al. $[13,14]$ showed the relationship between the dynamics of the crusher and the interactions of the rock material and machine by using DEM. The breakage and size reduction process of rock particles was also simulated. Li et al. [15] used the bonded particle model (BPM) of DEM, which can replicate the performance of a cone crusher well, to represent the size reduction of rock occurring within a cone crusher chamber. A more accurate prediction of the percentage of fine products was provided. In addition, the drop weight test (DWT) is widely used. DWT has been used to research the functional relationships between impact energy and crushed products and between contact location and fragmentation morphology $[16,17]$.

However, there are few studies on the detailed distribution of crushed products of ore under the condition of laminated crushing. Under the condition of laminated crushing, the particle size is various, and the effect is complex. Wang [8], Ma [18], Dong [19], Zhang [20] et al. obtained the mass fraction of a particle with different compression ratios but did not study the product distribution after crushing in detail. With the concept of "industrial 4.0" being put forward, the crushing equipment will also develop towards the direction of intellectualization. Industry 4.0 is a name given to the current trend of automation and data exchange in manufacturing technologies, which includes cyber-physical systems, the Internet of things, cloud computing and cognitive computing; industry 4.0 fosters what has been called a "smart factory". Smart crushing equipment will realize the concept of precision crushing and other crushing attributes. A large amount of research has been done on the intelligent control of cone crushers. In 1994, Bayliss [21] et al. proposed the use of artificial intelligence (AI) tools in cone crushers. The main implementation methods are using automatic control [22] and mechatronics [23]. However, limited by the structure of traditional cone crushers, only the processes of feeding, discharge, and crushing was regarded $[24,25]$. The structure of the intelligent cone crusher is shown in Figure $1 \mathrm{~b}$. Compared with the traditional cone crusher in Figure 1a, the biggest difference is that the eccentric sleeve in the non-adjustable moving cone is replaced by an actuator in the adjustable moving cone. Therefore, the compression ratio can be automatically adjusted according to the particle size of the material in the crushing chamber. Thereby, the particle size of the crushed product can be optimal, and the intelligent cone crusher can achieve the goal of "precise crushing".

For achieving the above functions, more in-depth and systematic research on broken products of bulk materials is needed. In this paper, the crushed distribution model for each particle was established by simulation, using EDEM. The model describes the distribution of fragmentation products with three-parameter beta distribution. By using EDEM, the compression force of each particles under confining pressure was calculated, and the compression ratio of each particles was determined. A relative compression ratio model was established to describe the functional relationship between the compression ratio of single-layer particles and the total compression ratio under laminated crushing, 
that is, to describe the effect of different particle distributions on the conversion efficiency of the compression ratio. On the basis of the above relative compression ratio model and the crushed product model of single-layer particles, the laminated crushed product model was obtained. In the product model of laminated crushing, the breakage function was constructed, and a continuous breakage function model which is suitable for the calculation was established. The compression ratio of single particles was introduced as the criterion to judge whether a particle was broken; therefore, it was not necessary to select a function to describe the unbroken particles. The model can provide a theoretical basis for the design of cone crushers, high-pressure roller mills, and other crushing equipment, with the goal to achieve "precision crushing". This model can be used as a basis for specific designs. In the design of a crusher, by using this model as the basis and the output as the design objective, while considering the author's previous achievements [26,27], the crushing cavity and other parts that allow appropriate output can be designed.

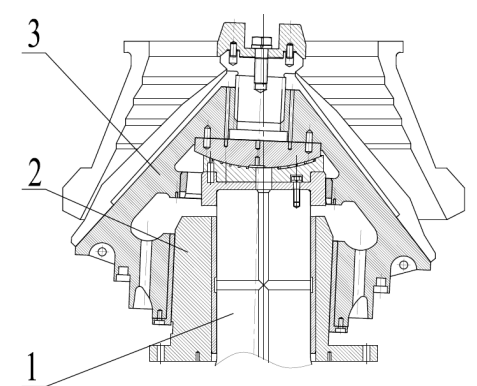

1. Spindle 2. Eccentric sleeve 3. Moving cone

(a)

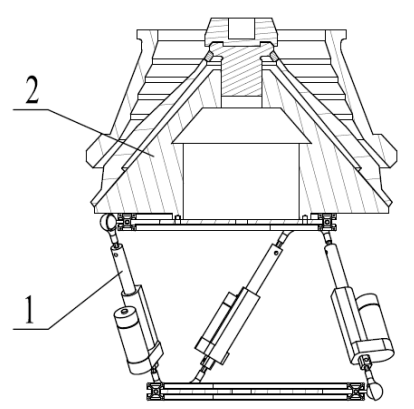

1. Actuator 2. Moving cone

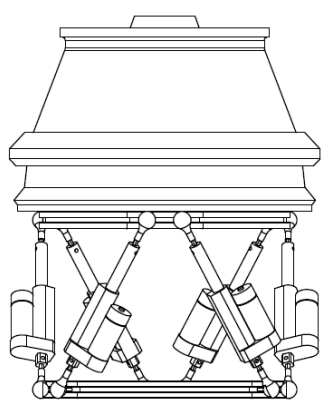

(b)

Figure 1. Relative compression ratio frequency of particles under different compression ratios: (a) Structure of the traditional cone crusher; (b) Structure of the intelligent cone crusher.

\section{Compression Ratio Model of Single Particles}

When single particles or single-layer particles with single-particle size are broken, the total compression ratio is equal to the compression ratio acting on each particle. During laminated crushing, the actual compression ratio acting on each particle is not equal to the total compression ratio, because of the influence of intergranular slip. Therefore, it is necessary to build a compression ratio model of each single particle in laminated crushing. To quantitatively describe the relationship between single-particle compression ratio and total compression ratio, the relative compression ratio of particles, $\lambda$, is introduced:

$$
\lambda=\frac{\eta_{s}}{\eta}
$$

where $\eta_{\mathrm{s}}$ is the single-particle compression ratio, $\eta$ is the total compression ratio.

EDEM simulation is in linear range, and the contact of particles is according to the Hertz model. Therefore, the single-particle compression ratio is

$$
\eta_{s}=\frac{\Delta d}{d}=1-\sqrt{1-\frac{4 c^{2}}{d^{2}}}
$$

where $c$ is the radius of the contact surface, according to the Hertz contact model:

$$
c=\sqrt[3]{\frac{3 F \frac{1-v^{2}}{E}}{\frac{1}{d}+\frac{1}{d_{2}}}}
$$

$F$ is the compressive force, $d$ is the particle size, $d_{2}$ is the size of other particles, $\Delta d$ is the change of particle size, $E$ is the elastic modulus, $v$ is Poisson's ratio. 
In mixed particles, one particle may contact other particles, and the contact probability is the ratio of the volume of other particles to the total volume of the material. So, $d_{2}$ is modified to $\bar{d}$, the average particle size of total particles. The compression force $F$ and the compression ratio $\eta$ are different from those of two single particles when they are in contact with each other. It is necessary to regard the above situation as two-particle contact. The EDEM confining pressure simulation condition is shown in the Figure 2. With the simulation, the compression force data of each particle can be obtained. So, according to Equations (1) and (2), the relative compression ratio can be calculated.

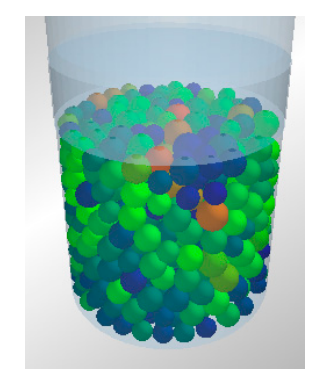

Figure 2. EDEM confining pressure simulation condition.

The frequency of the relative compression ratio of each particle under different compression ratios is shown in Figure 3.

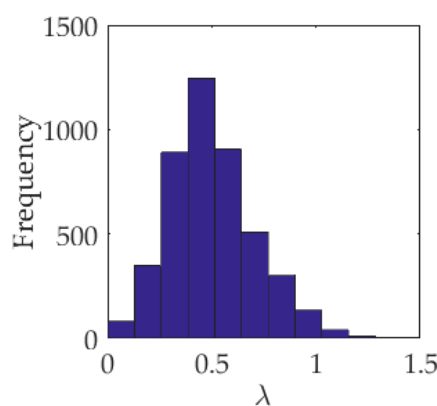

(a)

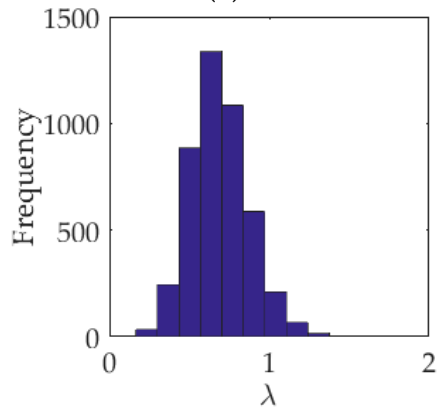

(c)

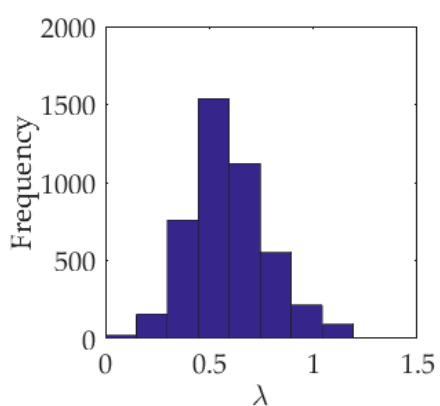

(b)

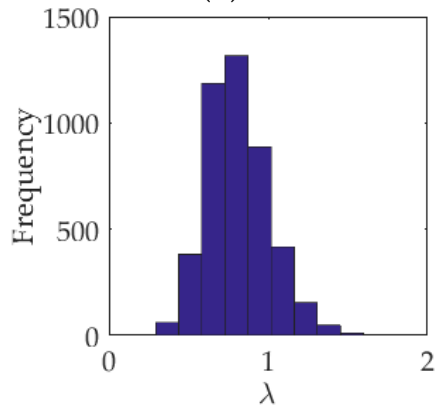

(d)

Figure 3. Frequency of the relative compression ratio of each particle under the different compression ratios: (a) $\eta=0.1$; (b) $\eta=0.2 ;$ (c) $\eta=0.3$; (d) $\eta=0.4$.

The above figures have lognormal distribution characteristics, so the relative compression ratio can be described by a lognormal distribution.

The relative compression ratio is only related to the total compression ratio, particle size, average particle size, and material height in confined pressure simulation. Therefore, it is not necessary to consider the influence of the compressive force and the modulus of elasticity. Assuming that the relative compression ratio of particles obeys a lognormal distribution, the relative compression ratio function is determined as:

$$
\lambda \sim \operatorname{Ln}\left(\mu_{\lambda}, \sigma_{\lambda}^{2}\right)
$$


where

$$
\begin{aligned}
\mu_{\lambda} & =f_{\lambda}(\eta, d, h, \bar{d}) \\
\sigma_{\lambda}^{2} & =f_{\sigma^{2}}(\eta, d, h, \bar{d})
\end{aligned}
$$

where $h$ is the height of the material in confining pressure simulation conditions.

Under the same $d / h$ - the ratio of particle size and height of the material-but different $d$ and $h$, the expectation and variance of the relative compression ratio of each particle from the simulation results are not too different from each other in different condition. The simulation condition is the confining pressure, and the single particle size of a granular material ranged from $40 \mathrm{~mm}$ to $80 \mathrm{~mm}$. Under the condition of $d / h=0.08$, the frequency of total compression ratio and relative compression ratio is shown in Figure 4.

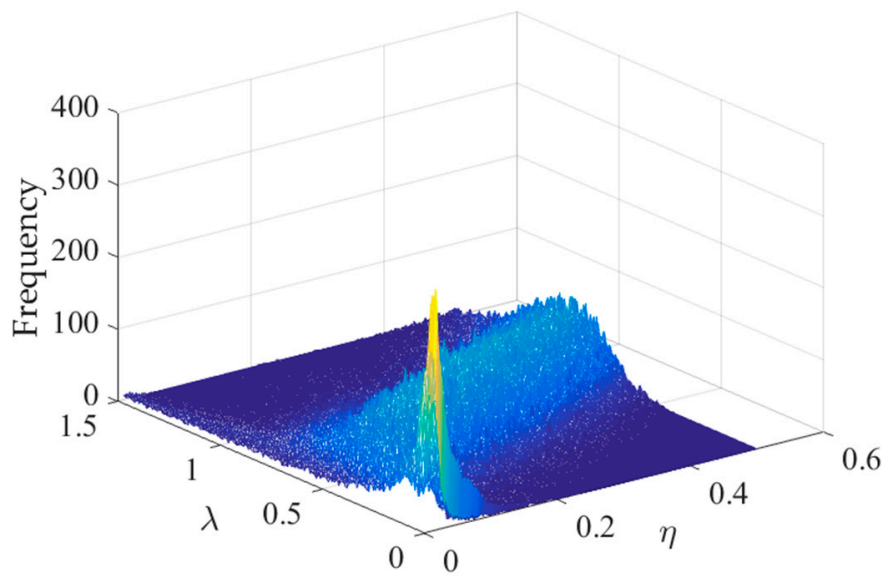

Figure 4. Frequency of total compression ratio and relative compression ratio.

The parameters $\mu$ and $\sigma$ are obtained under different total compression ratio, through simulation data.

The mean and variance of the relative compression ratio and total compression ratio re shown in Figure 5. The mean of the relative compression ratio of each particle and the total compression ratio can be described by an exponential function when the change of the mean reaches a steady state. After fitting, Equation (5) can be obtained.

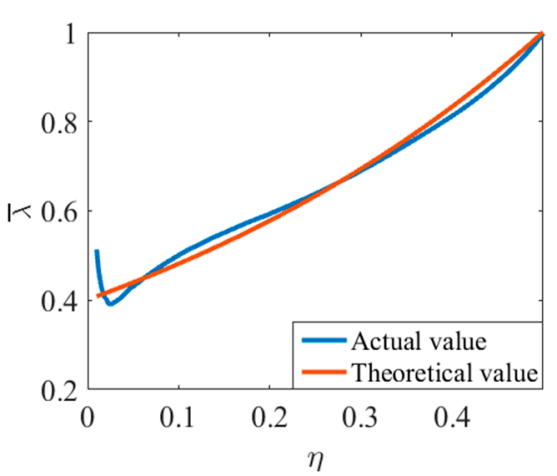

(a)

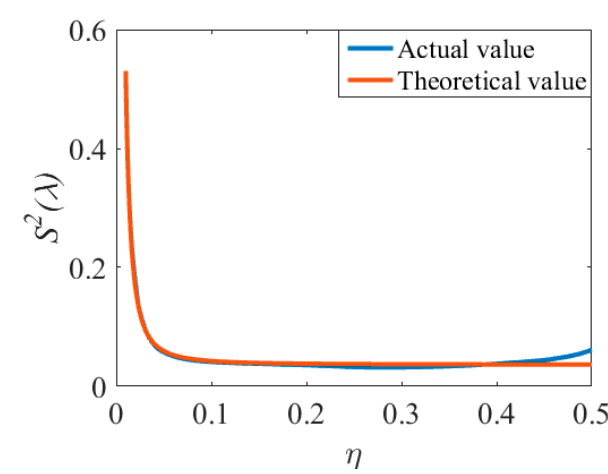

(b)

Figure 5. Mean and variance of the relative compression ratio and total compression ratio: (a) Mean; (b) Variance.

The extreme case is $d / h=1$. Under this circumstance, laminated crushing is changed into single-layer crushing. In this case, $a=1, b=0$, and the means of the relative compression ratio and total compression ratio are all close to 1 . Considering the above cases, Equations (5)-(7), representing the 
fitting results of the expectations and variances of the relative compression ratio of single-particle-size particles, are built as follows:

$$
E_{\lambda, \mathrm{s}}(\eta)=a \exp (-b \eta)
$$

$E_{\lambda, \mathrm{s}}(\eta)$ is the mean of the relative compression ratio of single-particle-size particles, which is a function of the total compression ratio $\eta$. It is also a predictive expectation.

$$
\begin{gathered}
a=0.5993 \exp \left(-0.5499\left(\frac{h}{d}\right)\right)+0.4007 \\
b=-2 \ln \left(\frac{1}{a}\right)
\end{gathered}
$$

Four-digit significant values are used for all fitting results.

The variance of the relative compression ratio of each particle $D_{\lambda, s}(\eta)$ and total compression ratio can be described by Equation (7) within certain range (0.1-0.5).

$$
D_{\lambda, \mathrm{s}}(\eta)=7.669 \times 10^{-5} \eta^{-1.904}+0.03643
$$

The result from confining pressure simulation of mixed particles with different sizes is that the predictive expectation of the relative compression ratio of each particle is independent of the variance of the total particle size. However, there is a power function between the ratio of expectation of compression ratio of mixed-size particles and the expectation of compression ratio of a certain-size particle, as well as between the ratio of a certain average particle size $\bar{d}$ and a certain size $d$. That is:

$$
\frac{E_{\lambda, \mathrm{m}}(\eta)}{E_{\lambda, \mathrm{s}}(\eta)}=\left(\frac{\bar{d}}{\bar{d}}\right)^{\mathrm{m}}
$$

where $E_{\lambda, \mathrm{m}}(\eta)$ is the mean of the relative compression ratio of mixed-size particles. The parameter $\mathrm{m}$ is the coefficient determined after fitting. The log-log figures of $\frac{E_{\lambda, \mathrm{m}}(\eta)}{E_{\lambda, s}(\eta)}$ and $\frac{\bar{d}}{d}$ are shown in Figure 6.

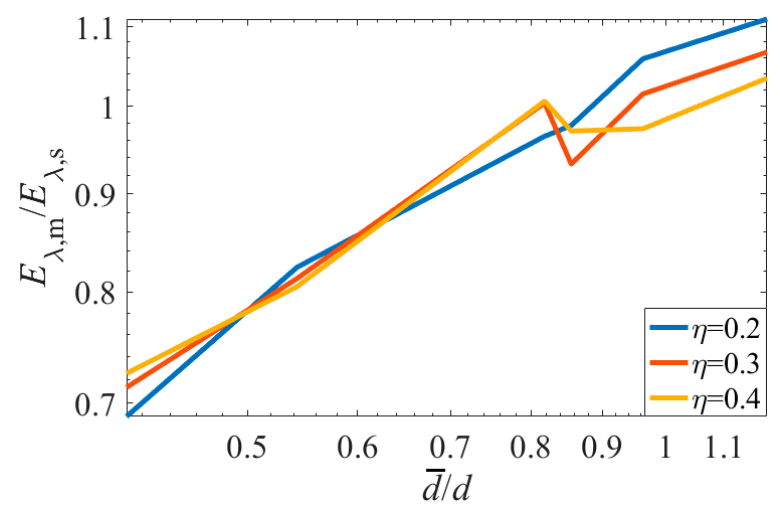

Figure 6. The functional relationship between $\frac{E_{\lambda, \mathrm{m}}(\eta)}{E_{\lambda, \mathrm{s}}(\eta)}$ and $\frac{\bar{d}}{d}$ under different total compression ratios.

Mixed particles with different average particle size $\bar{d}$ and material height in confined pressure simulation $h$ were simulated and fitted.

$$
E_{\lambda, \mathrm{m}}(\eta)=E_{\lambda, \mathrm{s}}(\eta)\left(\frac{\bar{d}}{\bar{d}}\right)^{0.5725}
$$

By combining Equation (5), the predictive expectation of the relative compression ratio $E_{\lambda}(\eta)$ is obtained: 


$$
E_{\lambda}(\eta)=a \exp (-b \eta)\left(\frac{\bar{d}}{d}\right)^{0.5725}
$$

As can be seen from Figure 5, the variance of the relative compression ratio is independent of the expectation and variance of the total particle size. Therefore, the variance of the relative compression ratio can be described by Equation (7). According to Equation (3), the probability density function of the compression ratio of a single particle is:

$$
f_{\eta_{s}}\left(d, \eta_{s}\right)=\frac{1}{\sqrt{2 \pi} \sigma \eta_{s}} \exp \left(\frac{\left(\ln \frac{\eta_{s}}{\eta}-\mu\right)^{2}}{2 \sigma^{2}}\right)
$$

where $\mu$ and $\sigma$ are determined by Equations (4), (6), (7) and (10), and are a function of $\eta, h, \bar{d}$.

Therefore, the corresponding image of logarithmic normal distribution probability density function of the relative compression ratio $\lambda$ under different total compression ratios $\eta$ is shown in Figure 7.

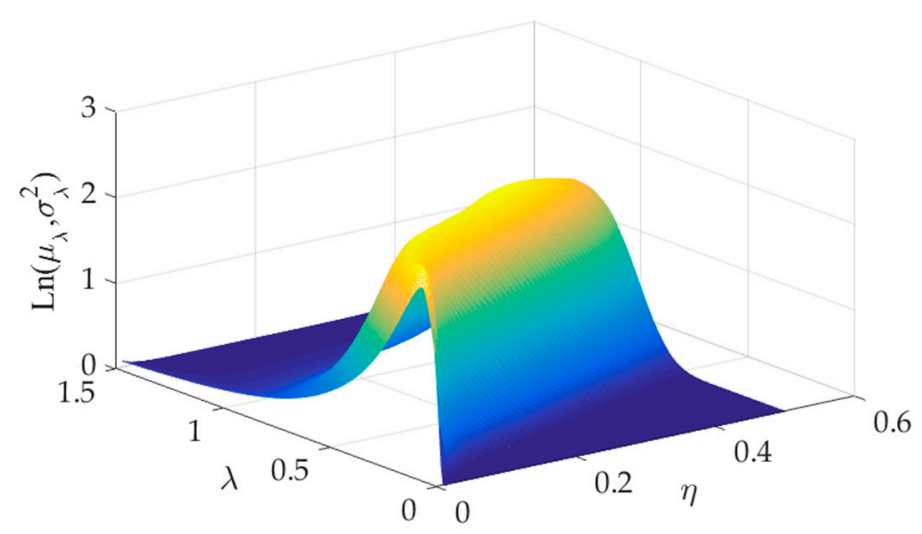

Figure 7. Total compression ratio and relative compression ratio and probability density function.

\section{Model of Single-Layer Particle CRUSHED Products}

Rosin and Rammler [28] proposed that the particle size distribution of broken products has two components, classifying the crushed products as qualified fine particles and unqualified coarse particles. According to this classification, the destruction and comminution of particles are not caused by a single process of destruction, but by two or more processes. Several typical fragmentation models are described hereafter.

Volume breakage model: The whole particle is broken. After being crushed, the products are mostly middle-sized particles with large particle size. The impact and extrusion crushed products are described by this model.

Surface area breakage model: At the time of breakage, only the surface of a particle is broken, and the fine ingredients are grinded down. This destructive action hardly involves the interior of particles. This is a typical grinding and comminution method.

Uniform breakage model: The force applied on the particles causes dispersive damage of the particles. These three models of breakage and histograms representing the frequency of granular grade and mass fraction are shown in Figure 8. When the force is appropriate, the product presents the characteristics of volume breakage. When the force is too large, the product presents the characteristics of uniform breakage. When the force is too small, the product presents the characteristics of surface area breakage. 


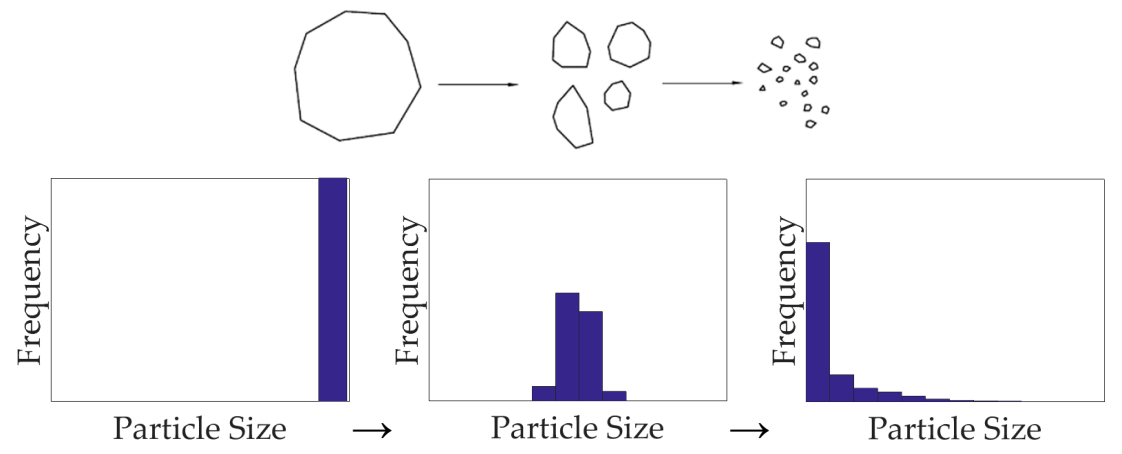

(a) Volume breakage model

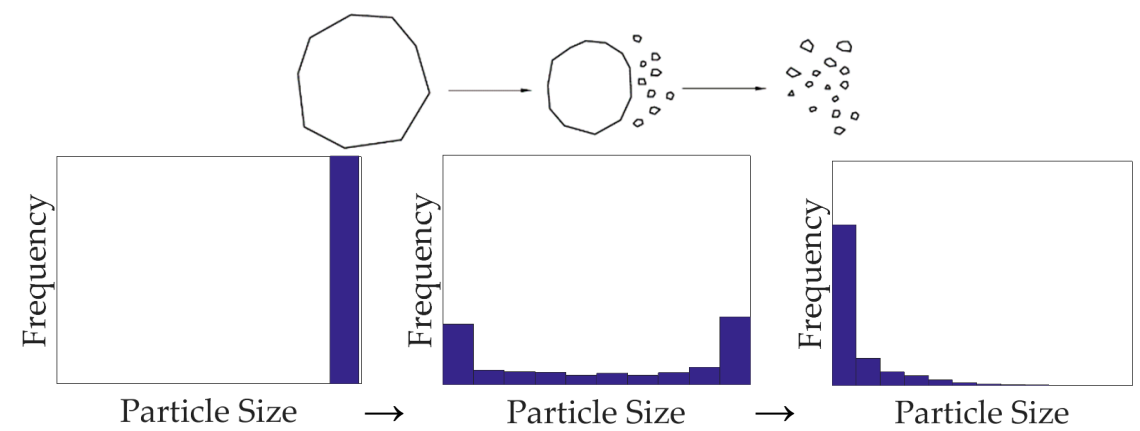

(b)

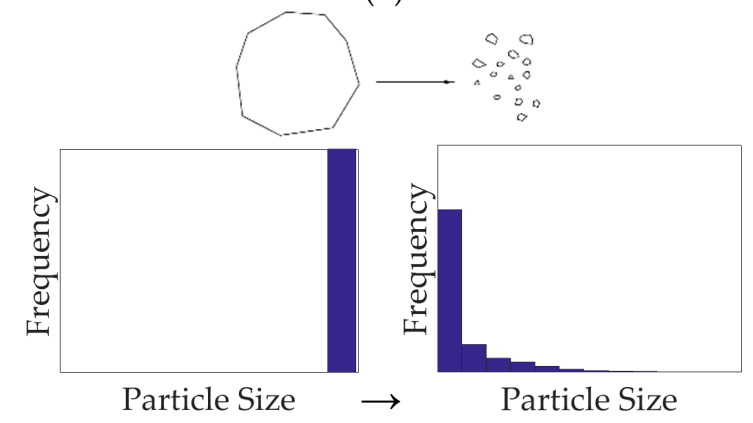

(c)

Figure 8. Changing particle size and mass fraction according to typical breakage models: (a) Volume breakage model; (b) Surface area breakage model; (c) Uniform breakage model.

Functions which are commonly used to describe the distribution of fragmentation products mainly include normal distribution, lognormal distribution, Weibull distribution, fractal characteristic function, etc. Actually, the crushed products are affected by the material properties (hardness, modulus of elasticity, Poisson's ratio, cohesion, etc.) and the force magnitude. Therefore, the particle size distribution of crushed products is diverse. After crushing, the crushed products particle size is between 0 and $d_{i}$ ( $d_{i}$ is the input particle size), and it can show different skewness with changes in the compression ratio. So, it cannot be described accurately by using normal distribution, lognormal distribution, or Weibull distribution. The actual distribution of broken products is non-linear. The fractal characteristic function can conveniently approximate the linear part of the middle section of the curve but cannot accurately describe the beginning and the end of the curve. Moreover, when the proportion of surface area fragmentation characteristics is large, there will be double peaks. Therefore, it is necessary to establish a unified and accurate distribution model of crushed products.

The integral interval of beta distribution is $(0,1)$, and there are two parameters $\alpha, \beta>0$ of beta distribution. The shape and skewness of the beta distribution curve can be changed by adjusting alpha and beta. When $\alpha, \beta<1$, the curve shows a bimodal state. Therefore, the crushed products can be 
described by a beta distribution. Assuming that the ratio of the particle size of broken products $d_{0}$ to the original particle size $d_{i}$ obeys a beta distribution, Equation (12) can be obtained:

$$
\frac{d_{o}}{d_{i}} \sim \operatorname{Be}(\alpha, \beta)
$$

A three-parameter beta distribution function of the fragmentation products is constructed.

$$
\operatorname{Be}(\alpha, \beta)=\int_{0}^{1} \frac{\Gamma(\alpha+\beta)}{\Gamma(\alpha) \Gamma(\beta)} x^{n}(1-x)^{n} \mathrm{~d} x \stackrel{x=\frac{d_{0}}{d_{i}}}{=} \frac{1}{d_{i}} \int_{0}^{d_{i}} \frac{\Gamma(\alpha+\beta)}{\Gamma(\alpha) \Gamma(\beta)}\left(\frac{d_{0}}{d_{i}}\right)^{n}\left(1-\frac{d_{o}}{d_{i}}\right)^{n} \mathrm{~d} d_{o}
$$

where $\Gamma$ is the Gamma function.

For a determined input particle size $d_{i}$, the expectation $E_{c p}\left(d_{0}\right)$ of the output particle size of three-parameter beta distribution function is:

$$
E_{c p}\left(d_{0}\right)=\frac{\alpha}{\alpha+\beta} d_{i}
$$

The variance $D_{c p}\left(d_{o}\right)$ of output particle size is:

$$
D_{c p}\left(d_{0}\right)=\frac{\alpha \beta}{(\alpha+\beta)^{2}(\alpha+\beta+1)} d_{i}^{2}
$$

In EDEM, the compression crushing of large particles consisting of small particles bonding together is used to simulate the breaking process of granules. In a practical situation, the breakage of brittle material particles shows tangential shearing. However, in the process of compression simulation, the breakage of bonds between small particles presents normal snap, which is not in conformity with the actual situation, and the large particles present elasticity. In a practical situation, the ore is brittle material. Therefore, by using EDEM simulation, the distribution of crushed products can be simulated accurately, but the corresponding compression ratio is far from the actual one. It is necessary to transform the simulation compression ratio to the actual compression ratio. Considering the actual single particle breakage [29], the transformation equation of the simulation compression ratio and actual compression ratio is obtained:

$$
\eta_{\mathrm{a}}=1-\frac{\left(1-\eta_{\mathrm{a}, \mathrm{cr}}\right)}{\left(1-\eta_{\mathrm{si}, \mathrm{cr}}\right)^{n}}\left(1-\eta_{\mathrm{si}}\right)^{n}
$$

where $\eta_{\mathrm{si}, \mathrm{cr}}$ is the simulation compression ratio when the particle begins to crumble, $\eta_{\mathrm{si}, \mathrm{cr}}=0.4688$; $\eta_{\mathrm{cr}}$ is the actual compression ratio when the particle begins to crumble $\eta_{\mathrm{a}, \mathrm{cr}}=0.05 ; \eta_{\mathrm{si}}$ is the simulation compression ratio; $\eta_{\mathrm{a}}$ is the actual compression ratio; $n$ is the transformation coefficient. Comparing the granularity in practice [29] and in the simulation, $n$ is determined to be 0.8 .

The bonding parameters of particles are set according to basalt. The normal cohesion is set to $25 \mathrm{Mpa}$. Using EDEM simulation under the condition of single-layer crushing, the actual distribution and the theoretical probability density function of beta distribution after parameter estimation of crushed products consisting of $160 \mathrm{~mm}$-diameter particles under different compression ratios of single particles are shown in the Figure 9. The mechanical parameters of the simulation are set according to mechanical parameters of basalt, which is same material as in the in experiments in Section 5. The function of the mean and variance of crushed products of $160 \mathrm{~mm}$-diameter particles and the different total compression ratio are shown in Figure 10. 


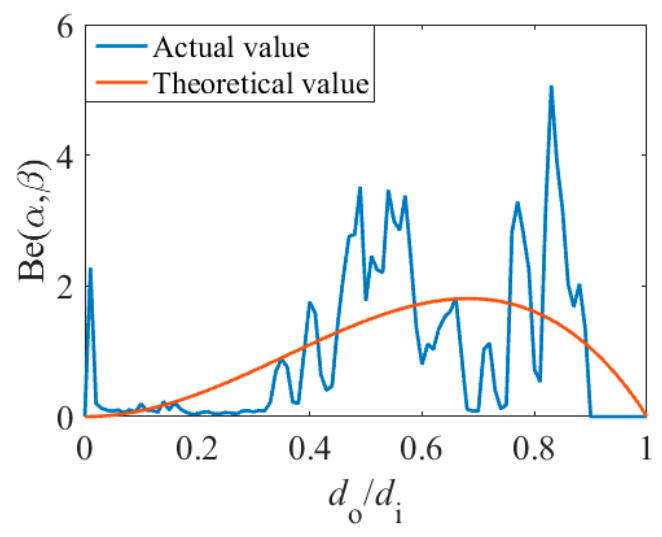

(a)

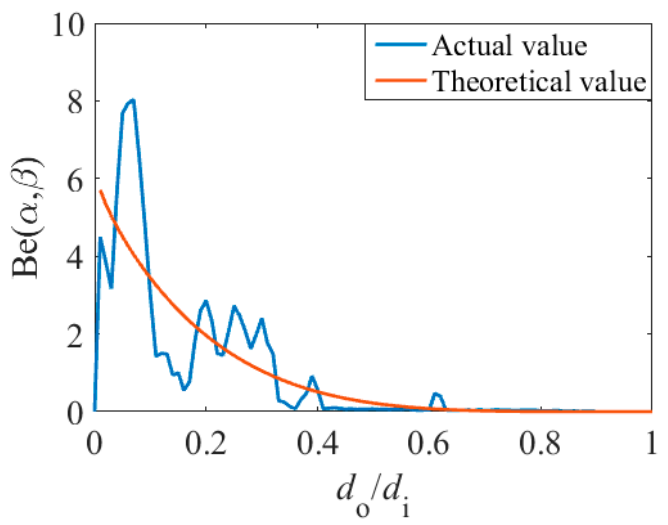

(c)

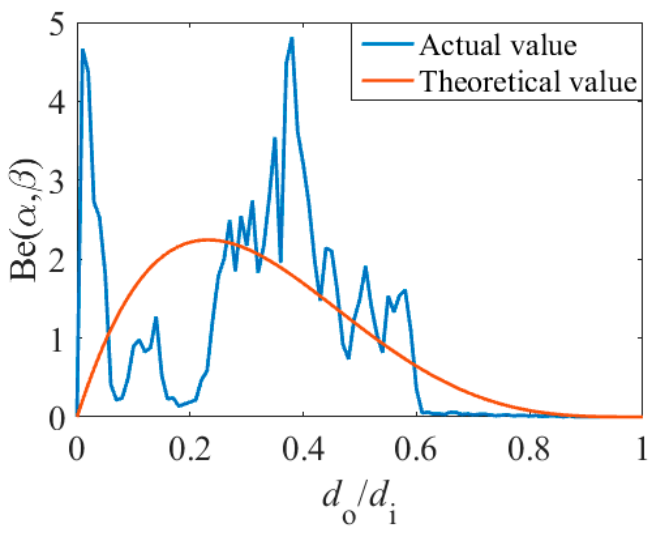

(b)

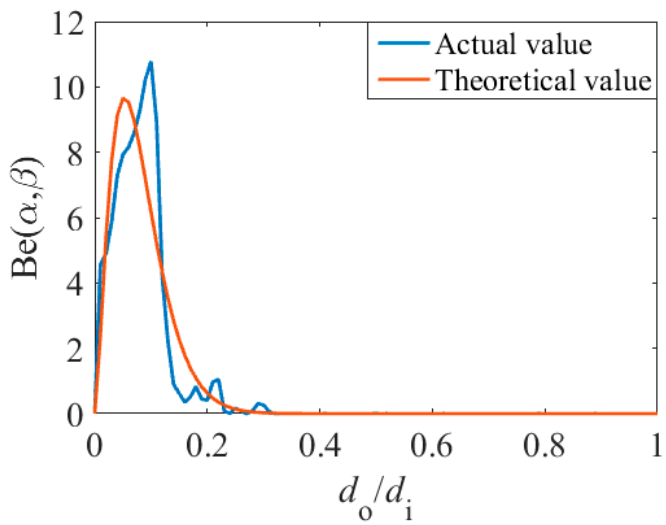

(d)

Figure 9. Several distribution curves of actual and theoretical crushed products under different single-layer compression ratios: (a) $\eta_{\mathrm{a}}=0.095$; (b) $\eta_{\mathrm{a}}=0.23$; (c) $\eta_{\mathrm{a}}=0.38$; (d) $\eta_{\mathrm{a}}=0.48$.

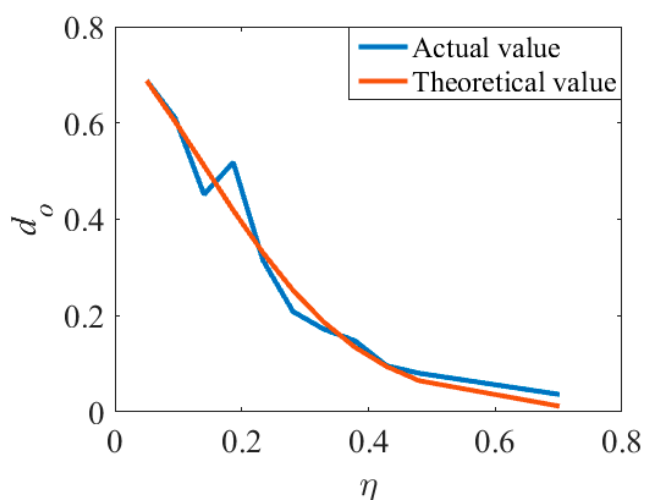

(a)

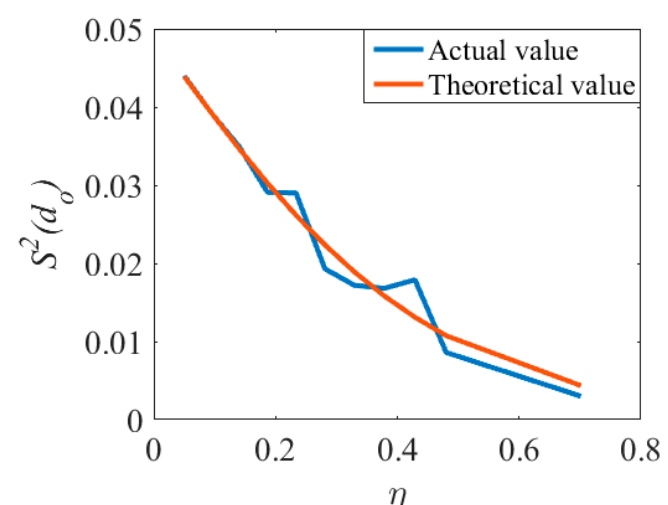

(b)

Figure 10. Mean and variance of crushed products under different single-layer crushing conditions: (a) Mean of crushed products; (b) Variance of crushed products.

Mean and variance decrease with the increase of the compression ratio, but the decreasing speed is not constant. They can be described by an S-curve. Equation (16) can be obtained by non-linear fitting:

$$
\begin{aligned}
E_{\mathrm{cp}}\left(\eta_{\mathrm{a}}\right) & =\frac{3.111}{\exp \left(7.929 \eta_{\mathrm{a}}\right)+3.036} \\
D_{\mathrm{cp}}\left(\eta_{\mathrm{a}}\right) & =\frac{0.07918}{\exp \left(3.875 \eta_{\mathrm{a}}\right)+0.5779}
\end{aligned}
$$


Therefore, the corresponding figure of beta distribution probability density function of the ratio of $d_{0} / d_{i}$ under different total compression ratio $\eta$ is shown in Figure 11.

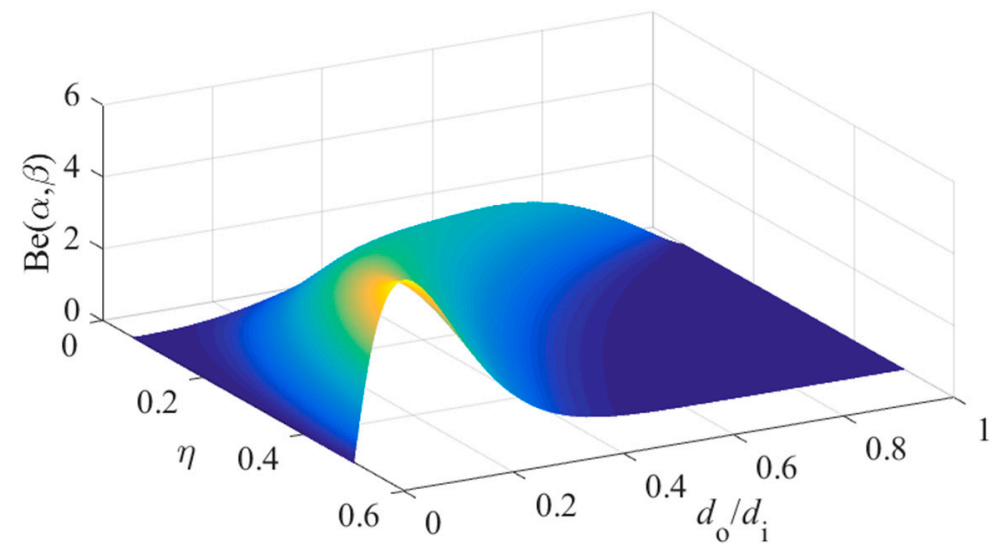

Figure 11. Beta distribution probability density function under different compression ratios.

Therefore, the particle size distribution of single-particle crushed products can be expressed as:

$$
d_{0} \sim \operatorname{Be}(\alpha, \beta) d_{i}
$$

According to Equations (14) and (15):

$$
\begin{gathered}
\beta=\left(\frac{E_{\mathrm{cp}}\left(d_{i}-E_{\mathrm{cp}}\right)}{D_{\mathrm{cp}}}-1\right)\left(1-\frac{E_{\mathrm{cp}}}{d_{i}}\right) \\
\alpha=\frac{E_{\mathrm{cp}}}{d_{i}-E_{\mathrm{cp}}} \beta
\end{gathered}
$$

Therefore, according to Equations (12) and (13), the probability density function of single-particle fragmentation products is:

$$
b\left(d_{i}, d_{o}, \eta_{s}\right)=\frac{1}{d_{i}} \int_{0}^{d_{i}} \frac{\Gamma(\alpha+\beta)}{\Gamma(\alpha) \Gamma(\beta)}\left(\frac{d_{o}}{d_{i}}\right)^{n}\left(1-\frac{d_{o}}{d_{i}}\right)^{n} \mathrm{~d} d_{o}
$$

$\alpha, \beta$ are determined by Equation (19) and are functions of $\eta_{\mathrm{s}}$.

\section{Establishment of Breakage Function}

The population balance model proposed by previous studies $[5,30,31]$ is shown in Equation (14). Among them, $\mathbf{F}$ is the mass fraction of each particle grade of the input particle, $\mathbf{B}$ is the matrix of the breakage function, $\mathbf{P}$ is the mass fraction of each particle grade of the output particle.

$$
\left[\begin{array}{cccc}
b_{11} & 0 & \ldots & 0 \\
b_{21} & b_{22} & & \\
\vdots & & \ddots & \vdots \\
b_{n 1} & b_{n 2} & \ldots & b_{n n}
\end{array}\right]\left[\begin{array}{c}
f_{1} \\
f_{2} \\
\vdots \\
f_{n}
\end{array}\right]=\left[\begin{array}{c}
p_{1} \\
p_{2} \\
\vdots \\
p_{n}
\end{array}\right]
$$

That is:

$$
\mathbf{B F}=\mathbf{P}
$$

The matrix of the selection function is introduced to describe unbroken particles. Equation (22) is modified to Equation (23):

$$
(\mathbf{B S}+(\mathbf{I}-\mathbf{S})) \mathbf{F}=\mathbf{P}
$$


Among them, $\mathbf{S}$ is the matrix of the selection function, which is diagonal matrix. Each element of $\mathbf{S}$ is the mass fraction of crushed particles at all levels; $\mathbf{I}$ is a unit matrix.

In Sections 1 and 2, the single-particle compression ratio and the crushed product model are continuous function models. On this basis, it is inconvenient to determine the specific values of each element in Equation (21). So, a continuous breakage function needs to be established. The corresponding continuous breakage function is Equation (24):

$$
p\left(d_{0}\right)=\int_{0}^{+\infty} b\left(d_{i}, d_{0}\right) f\left(d_{i}\right) \mathrm{d} d_{i}
$$

where $f\left(d_{\mathrm{i}}\right)$ is the probability density function of input particle mass, $b\left(d_{\mathrm{i}}, d_{\mathrm{o}}\right)$ is the breakage function, $p\left(d_{\mathrm{o}}\right)$ is the probability density function of output particle mass. After introducing factors affecting the crushing products, i.e., the compression ratio of single particle $\eta_{\mathrm{s}}$, Equation (24) is modified to Equation (25):

$$
p\left(d_{o}\right)=\int_{0}^{+\infty} \int_{0}^{+\infty} b\left(d_{i}, d_{o}, \eta_{s}\right) f_{\eta_{s}}\left(d_{i}, \eta_{s}\right) \mathrm{d} \eta_{s} \mathrm{~d} d_{i}
$$

where $b\left(d_{i}, d_{0}, \eta_{s}\right)$ is determined by Equation (19), and $f_{\eta_{s}}\left(d_{i}, \eta_{s}\right)$ is determined by Equation (11).

When the compression ratio of single particles does not meet the crushing requirements, particles are not broken. That is, $d_{o}=d_{i}$ in the breakage function $b\left(d_{i}, d_{0}, \eta_{s}\right)$. Assuming that the compression ratio of single particle is $\left(\eta_{s 1}, \eta_{s 2}\right)$, the mass fraction of unbroken particles is:

$$
p\left(d_{o}\right)=\int_{0}^{+\infty} \int_{\eta_{s 1}}^{\eta_{s 2}} b\left(d_{i}, d_{o}, \eta_{s}\right) f_{\eta_{s}}\left(d_{i}, \eta_{s}\right) \mathrm{d} \eta_{s} \mathrm{~d} d_{i}
$$

So, Equation (25) contains the mass fraction of unbroken particles. There is no need to use the selection function to describe the mass fraction of unbroken particles.

\section{Experimental Verification}

The experimental data in reference [18] were used to verify the above models. In reference [18], the particle size distribution coefficient is defined as $\sigma_{\mathrm{cp}}=\frac{\left(\sum_{i=1}^{n} p_{i}\left(d_{i}-\bar{d}\right)^{2}\right)^{\frac{1}{2}}}{\bar{d}}, \bar{d}=\sum_{i=1}^{n} p_{i} d_{i}$. The particle size distribution coefficient of the continuous distribution model is $\sigma_{\mathrm{cp}}=\frac{\left(\int_{0}^{d_{0} \max } p\left(d_{0}\right)\left(d_{0}-\bar{d}\right)^{2} \mathrm{~d} d_{0}\right)^{\frac{1}{2}}}{\bar{d}_{o}}$, that is $\sigma=\frac{\sqrt{D_{\mathrm{cp}}}}{E_{\mathrm{cp}}}$. The theoretical and practical particle size distribution coefficients of crushed products at different compression ratios are shown in Table 1, and the corresponding image is shown in Figure 12.

Table 1. Test results of laminated crushing.

\begin{tabular}{cccccc}
\hline $\begin{array}{c}\text { Serial } \\
\text { Number }\end{array}$ & $\begin{array}{c}\text { Particle Size } \\
\text { Range of } \\
\text { Granular } \\
\text { Materials/mm }\end{array}$ & $\begin{array}{c}\text { Material } \\
\text { Height before } \\
\text { Crushing/mm }\end{array}$ & $\begin{array}{c}\text { Feed } \\
\text { Compression/mm }\end{array}$ & $\begin{array}{c}\text { Compression } \\
\text { Ratio }\end{array}$ & $\begin{array}{c}\text { Particle-Size } \\
\text { Distribution } \\
\text { Coefficient } \sigma\end{array}$ \\
\hline $1-1$ & $19.0-26.5$ & 71 & 5.68 & 0.080 & 0.218 \\
$1-2$ & $0-26.5$ & 65.32 & 5.22 & 0.150 & 0.336 \\
$1-3$ & $0-26.5$ & 60.1 & 4.8 & 0.220 & 0.490 \\
$1-4$ & $0-26.5$ & 55.3 & 4.42 & 0.250 & 0.559 \\
\hline $2-1$ & $19.0-26.5$ & 71.0 & 9.9 & 0.140 & 0.375 \\
$2-2$ & $0-26.5$ & 61.1 & 8.55 & 0.245 & 0.521 \\
\hline $3-1$ & $19.0-26.5$ & 71.0 & 12.8 & 0.180 & 0.420 \\
$3-2$ & $0-26.5$ & 58.2 & 10.48 & 0.260 & 0.524 \\
\hline $4-1$ & $19.0-26.5$ & 71.0 & 3.55 & 0.050 & 0.129 \\
$4-2$ & $0-26.5$ & 67.45 & 3.37 & 0.097 & 0.209 \\
\hline
\end{tabular}


Table 1. Cont.

\begin{tabular}{cccccc}
\hline $\begin{array}{c}\text { Serial } \\
\text { Number }\end{array}$ & $\begin{array}{c}\text { Particle Size } \\
\text { Range of } \\
\text { Granular } \\
\text { Materials/mm }\end{array}$ & $\begin{array}{c}\text { Material } \\
\text { Height before } \\
\text { Crushing/mm }\end{array}$ & $\begin{array}{c}\text { Feed } \\
\text { Compression/mm }\end{array}$ & $\begin{array}{c}\text { Compression } \\
\text { Ratio }\end{array}$ & $\begin{array}{c}\text { Particle-Size } \\
\text { Distribution } \\
\text { Coefficient } \sigma\end{array}$ \\
\hline $4-3$ & $0-26.5$ & 64.08 & 3.2 & 0.140 & 0.320 \\
$4-4$ & $0-26.5$ & 60.88 & 3.03 & 0.185 & 0.412 \\
$4-5$ & $0-26.5$ & 57.84 & 2.89 & 0.226 & 0.513 \\
$4-6$ & $0-26.5$ & 54.95 & 2.75 & 0.253 & 0.569 \\
\hline $5-1$ & $19.0-26.5$ & 70.0 & 7.00 & 0.100 & 0.276 \\
$5-2$ & $0-26.5$ & 63.0 & 6.30 & 0.190 & 0.430 \\
$5-3$ & $0-26.5$ & 56.7 & 5.67 & 0.250 & 0.536 \\
\hline
\end{tabular}

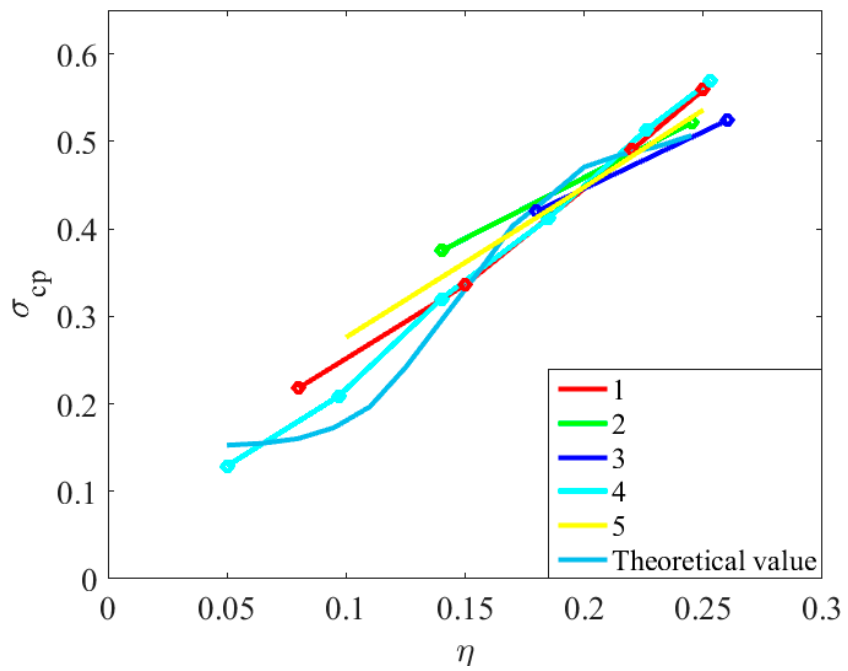

Figure 12. Particle-size distribution coefficient of theoretical and practical crushing products.

When the compression ratio is small, there are fewer crushed particles, and the particle size distribution coefficient changes little. With the increase of the compression ratio, the number of broken particles increases, and the variance of the particle-size distribution increases, the mean value decreases, and the coefficient of the particle-size distribution increases. When the compression ratio continues to increase, the particles become difficult to break up, and the increase of the particle-size distribution coefficient tends to be gentle. Compared with the test results and the theoretical results, the trend of the theoretical value is the same as that of the experimental value. When $\eta<0.15$, there still exist some difference between the test and the simulation result. When $\eta>0.15$, the theoretical value is almost the same as the experimental value.

\section{Conclusions}

For studying and discussing the characteristics of crushed products of granular materials under compression, the discrete element method (DEM) was used to carry out a series of simulation studies on confining pressure, and some positive were presented in this paper.

(1). The relative compression ratio model was established, and the functional relationship between the compression ratio of each particle and the total compression ratio was established.

(2). A single-particle breakage product model was established, and the relationship between the three-parameter beta distribution and the compression ratio of single particles was established.

(3). Based on the above model, the product model of laminated crushing was established. The breakage function related to the total compression ratio was established. 
(4). The particle distribution coefficients of crushed products under different overall compression ratios in theory and practice were compared by using experimental data.

Author Contributions: G.D. conceived and designed the calculations; B.S. had contributed to the supervision; Y.S. and G.Y. contributed to reviewing and revising. G.D. wrote the paper.

Funding: This research was funded by The National Key Research and Development Program of China (No. 2016YFC0600805).

Conflicts of Interest: The authors declare no conflict of interest.

\section{References}

1. Huang, S. Mechanics of Granular Material; Mechanical Industry Press: Beijing, China, 1993; p. 1.

2. Broadbent, S.; Callcott, T. Coal Breakage Processes, I. A New Analysis of Coal Breakage Processes. J. Inst. Fuel 1956, 12, 524-528.

3. Broadbent, S.; Callcott, T. Coal Breakage Processes, II. A New Analysis of Coal Breakage Processes. J. Inst. Fuel 1956, 12, 528-539.

4. Lynch, A. Mineral Crushing and Grinding Circuits; Elsevier Scientific Publishing Company: New York, NY, USA, 1977; p. 1.

5. Bengtsson, M.; Lee, E.; Evertsson, C.M. Influence of throw and compression ratio on particle shape-a full scale investigation and laboratory tests. Miner. Eng. 2010, 23, 549-557. [CrossRef]

6. Bengtsson, M.; Hulthén, E.; Evertsson, C.M. Size and shape simulation in a tertiary crushing stage, a multi objective perspective. Miner. Eng. 2015, 77, 72-77. [CrossRef]

7. Lee, E.; Evertsson, M. A comparative study between cone crushers and theoretically optimal crushing sequences. Miner. Eng. 2011, 24, 188-194. [CrossRef]

8. Wang, X. Research on Optimization of Crushing Performance of Cone Crusher Based on Laminated Crushing Theory. Master's Thesis, Yanshan University, Qinhuangdao, China, 2017.

9. Ito, M.; Kashiwaya, K.; Sumiya, N. Estimating the size distribution of anode and cathode activating agents in the crushed products of nickel metal hydride batteries from hybrid vehicles and its classification. Int. J. Miner. Process. 2010, 97, 92-95. [CrossRef]

10. Mukai, S.; Ichidate, M. Effect of Multi-Stage Crushing on the Size Distribution Control of Crushed Product of Iron Ore. Iron Steel Inst. Jpn. J. 1968, 54, 1232-1241. [CrossRef]

11. Ogawa, K.; Sha, Z.; Palosaari, S.; Ok, T. Size distribution function of droplet in liquid-liquid mixing and bubble in gas-liquid mixing, crystal in crystallization and crushed product in crushing. J. Chem. Eng. Jpn. 2001, 34, 627-633. [CrossRef]

12. Es-Haghi, H.; Rezai, B.; Refahi, A. Predicting size distribution of jaw crusher product by using Discrete Element Modelling (DEM). In Proceedings of the 24th International Mining Congress of Turkey, Antalya, Turkey, 14-17 April 2015; TMMOB Maden Muhendisleri Odasi: Ankara, Turkey, 2015.

13. Quist, J.; Evertsson, C. Application of discrete element method for simulating feeding conditions and size reduction in cone crushers. In Proceedings of the XXV International Mineral Processing Congress, Brisbane, Australia, 6-10 September 2010; Australasian Institute of Mining and Metallurgy: Carlton, Australia, 2010.

14. Quist, J.; Evertsson, C. Cone crusher modelling and simulation using DEM. Miner. Eng. 2016, 85, 92-105. [CrossRef]

15. Li, H.; McDowell, G.; Lowndes, I. Discrete-element modelling of rock communition in a cone crusher using a bonded particle model. Geotechnique 2014, 4, 79-82. [CrossRef]

16. Cleary, P.; Sinnott, M.; Morrison, R. Analysis of cone crusher performance with changes in material properties and operating conditions using DEM. Miner. Eng. 2017, 100, 49-70. [CrossRef]

17. Artoni, R.; Neveu, A.; Descantes, Y. Effect of contact location on the crushing strength of aggregates. J. Mech. Phys. Solids 2019, 122, 406-417. [CrossRef]

18. Ma, Y.; Fan, X.; He, Q.; Dong, G. Mathematical modeling of particle size and particle shape of crushing quality for cone crusher. Chin. J. Mech. Eng. 2013, 49, 95-102. [CrossRef]

19. Dong, G.; Fan, X.; Zhang, X.; Qin, L. Crushing force and kinematics analysis of cone crusher based on interparticle breakage. Chin. J. Mech. Eng. 2010, 46, 159-164. [CrossRef] 
20. Zhang, Z.; Ren, T.; Cheng, J.; Jin, X. Research on the inter-particle breakage of cone crusher considering the characteristics of particle shape transformation. Chin. J. Mech. Eng. 2017, 53, 173-180. [CrossRef]

21. Bayliss, D.; Parkin, R.; Bearman, R. Artificial intelligence in the control of cone crushers. In Proceedings of the Joint Hungarian-British International Mechatronics Conference, Budapest, Hungary, 21-23 September 1994; Computational Mechanics Publications: Southampton, UK, 1994.

22. Moshgbar, M.; Parkin, R.; Bearman, R. Impact of system tribology on automatic control of cone crushers. Trans. Inst. Meas. Control 1995, 17, 2-9. [CrossRef]

23. Moshgbar, M.; Parkin, R. Intelligent distributed system for real-time control of cone crusher. Microprocess. Microsyst. 1994, 18, 377-383. [CrossRef]

24. Hu, C. The Research of the Material Level Control System on the Crushing Process of the Ore Dressing. Master's Thesis, Central South University, Changsha, China, 2014.

25. Ostroukh, A.; Surkova, N. Automated process control system of mobile cone crusher. In Proceedings of the 18th International Multidisciplinary Scientific Geoconference, Albena, Bulgaria, 30 June-9 July 2018.

26. Liu, R.; Shi, B.; Shen, Y. Prediction model for liner wear considering the motion characteristics of material. Math. Probl. Eng. 2018, 2018, 9278597. [CrossRef]

27. Liu, R.; Shi, B.; Li, G.; Yu, H. Influence of operating conditions and crushing chamber on energy consumption of cone crusher. Energies 2018, 11, 1102. [CrossRef]

28. Rosin, P.; Rammler, E. The laws governing the fineness of powdered coal. J. Inst. Fuel 1933, 7, $29-36$.

29. Tang, C.; Xu, X.; Kou, S. Numerical investigation of particle breakage as applied to mechanical crushing-Part I: Single-particle breakage. Int. J. Rock Mech. Min. Sci. 2001, 38, 1147-1162. [CrossRef]

30. Evertsson, C. Size reduction in cone crushers. In Proceedings of the Minerals Engineering Conference, Falmouth, UK, 22-24 September 1999; Chalmers Tekniska Hogskola: Goteborg, Sweden, 1999.

31. Evertsson, C.M. Modelling of flow in cone crushers. Miner. Eng. 1999, 12, 1479-1499. [CrossRef]

(C) 2019 by the authors. Licensee MDPI, Basel, Switzerland. This article is an open access article distributed under the terms and conditions of the Creative Commons Attribution (CC BY) license (http://creativecommons.org/licenses/by/4.0/). 